\title{
MEK Inhibitor-Associated Central Retinal Vein Occlusion Associated with Hyperhomocysteinemia and MTHFR Variants
}

\author{
Jasmine H. Francis ${ }^{a, b}$ Eli L. Diamond ${ }^{b, c}$ Ping Chi $^{b, d, e}$ Korey Jaben ${ }^{a}$ \\ David M. Hyman ${ }^{b}$ d David H. Abramson ${ }^{a, b}$ \\ ${ }^{a}$ Ophthalmic Oncology Service, Memorial Sloan Kettering Cancer Center, New York, NY, USA; ${ }^{b}$ Weill Cornell Medical \\ Center, New York, NY, USA; 'Department of Neurology, Memorial Sloan Kettering Cancer Center, New York, NY, USA; \\ ${ }^{\mathrm{d}}$ Department of Medicine, Memorial Sloan Kettering Cancer Center, New York, NY, USA; ${ }^{\mathrm{C}}$ Human Oncology and \\ Pathogenesis Program, Memorial Sloan Kettering Cancer Center, New York, NY, USA
}

\section{Established Facts}

- Central retinal vein occlusion (CRVO) is a rare side effect of MEK inhibitors.

- MEK inhibitor-associated CRVO may result in permanent drug discontinuation.

\section{Novel Insights}

- MEK inhibitor-associated CRVO may be associated with hyperhomocysteinemia, suggesting a potential role for hyperhomocysteinemia screening prior to initiation of MEK inhibitor therapy.

- In this small cohort, MEK inhibitor-associated CRVO was associated with good visual recovery following intravitreous anti-VEGF.

\section{Keywords}

MEK inhibitor - Central retinal vein occlusion - Methylene tetrahydrofolate reductase

\section{Abstract \\ Background: Central retinal vein occlusion (CRVO) is a visu- ally threatening event that has rarely been observed in pa- tients taking MEK1/2 inhibitors and that may necessitate permanent discontinuation of a potentially efficacious ther- apy. We investigated the clinical characteristics of CRVO in patients on mitogen-activated protein kinase kinase (MEK) inhibition to better understand their predisposing factors and clinical course. Case Series: This was a single-center, ret-}

๑) 2019 S. Karger AG, Basel rospective cohort study (between December 2006 and September 2018). Three of 546 patients enrolled in 46 prospective trials involving treatment with MEK inhibitors at Memorial Sloan Kettering Cancer Center were identified as having CRVO. Clinical examination and course, multimodal ophthalmic imaging, and serum laboratory results (including homocysteine levels and genetic variants of methylene tetrahydrofolate reductase [MTHFR]) were reviewed for the 3 affected patients. All 3 patients with MEK inhibitor-associated CRVO had elevated serum homocysteine and gene variants of MTHFR (1 homozygous for A1298C, 1 heterozygous for A1298C, and 1 homozygous for C677T). Following intravitreous injections of anti-VEGF and discontinuation of drug, all patients regained vision to their baseline. Discussion: MEK

\section{KARGER}

karger@karger.com

www.karger.com/oop
Jasmine H. Francis, MD

Ophthalmic Oncology Service

Memorial Sloan Kettering Cancer Center

1275 York Ave., New York, NY 10065 (USA)

E-Mail francij1@mskcc.org 
inhibitor-associated CRVO is a rare event which can exhibit visual recovery after drug cessation and intravitreous antiVEGF injections. In this cohort, it was associated with hyperhomocysteinemia and genetic mutations in MTHFR, suggesting a potential role for hyperhomocysteinemia screening prior to initiation of MEK inhibitor therapy.

(c) 2019 S. Karger AG, Basel

\section{Introduction}

Dysregulation of the mitogen-activated protein kinase pathway occurs in some human cancers, making them amenable to directed therapies such as mitogen-activated protein kinase kinase (MEK) inhibitors [1]. The ocular side effects of MEK inhibitors include associated retinopathy, characterized by self-limited neurosensory detachments of the retina [2]. Another, but rare, event in patients on MEK inhibition is central retinal vein occlusion (CRVO). This is thought to result from venous thrombus formation at the level of the lamina cribrosa and leads to vasculopathy of the entire retina.

In general, CRVOs have a prevalence of $0.1 \%$ in the United States and are associated with a number of risk factors including age, smoking, diabetes, obesity, hypertension, hypercoagulable state, ocular hypertension, and retinal arteriolar abnormalities [3]. Following CRVO, neovascularization in the retina or the iris, macula edema, or ischemia can result in visual loss either related to elevated intraocular pressure, intraocular hemorrhage, or distortion in retinal architecture. These events can be visually threatening and their reversibility has been related to factors such as degree of retinal vascular perfusion and baseline visual acuity $[4,5]$.

In the published data of phase 1,2, or 3 trials of MEK inhibitors (including CI-1040, AZD6244, PD-0325901, GSK1120212, ROS126766, and MEK162), 4 of 784 patients reportedly developed retinal vein occlusions (RVOs), resulting in an overall calculated prevalence of $0.5 \%$ [6]. More specifically, these 3 events (of 66 patients in phase 1) occurred with PD-0325901 and 1 event (of 303 patients in phase 1 and 2) occurred with GSK1120212, resulting in a prevalence range of $0-4.5 \%$ depending on the MEK inhibitor used. Development of CRVO in this population of patients may have profound consequences; besides threatening vision, it may necessitate discontinuation of potentially life-conserving MEK inhibition. The present study investigated the clinical characteristics of the 3 patients with CRVO at our institution, with attention to potentially modifiable clinical risk factors.

\section{Methods}

A retrospective research protocol was used. Of 546 patients enrolled in 46 prospective trials (between December 2006 and September 2018) involving treatment with MEK inhibitors at Memorial Sloan Kettering Cancer Center, 3 were identified as having CRVO. Of note, 29 of the total patients were enrolled in 12 prospective trials that involved a combination of MEK inhibitor and RAF inhibitor. Medical records, including clinical and imaging findings as well as laboratory testing, were reviewed. Visual acuity was measured in Snellen notation. All patients with CRVO were tested for methylene tetrahydrofolate reductase (MTHFR) variants.

\section{Results}

Case details are listed in Tables 1 and 2. A representative case is demonstrated in Figure 1. Two males and 1 female (age 31-61 years) developed CRVO at a median of 7.1 months (range 6.2-8.3 months) into treatment with MEK inhibition. During the treatment course, all patients had acneiform rash, 2 had elevated creatine phosphokinase, and 2 had decreased ejection fraction likely attributable to drug. In all cases the CRVO was perfused by fluorescein angiography, and cystoid macula edema was identified by optical coherence tomography. All patients had elevated serum homocysteine measured at a range of 8-32 days after the onset of visual symptoms. Furthermore, all patients possessed gene variants of MTHFR (1 homozygous for A1298C, 1 heterozygous for A1298C, and 1 homozygous for C677T). All patients experienced a decline in vision at the time of $\mathrm{CRVO}$, ranging from 20/40 to count fingers. All patients stopped MEK inhibition and received intravitreous aflibercept (2-4 monthly injections) and vision returned to baseline, with stability at a mean of 24 months follow-up (range 6-43 months). It should be noted that patient 2 resumed MEK inhibition at a lower dose and has remained stable without recurrence of vein occlusion to date. The remaining patients permanently discontinued MEK inhibitor therapy.

\section{Discussion}

The present case series of this rare clinical entity (namely the 3 events of MEK inhibitor-associated CRVO) had striking similarities. The potential contributing factors, the clinical management, and the outcome were similar among all cases. To be more specific, all patients demonstrated hyperhomocysteinemia in the context of an MTHFR gene variant and regained vision to baseline following drug cessation and anti-VEGF injections. 
Table 1. Patient and treatment characteristics

\begin{tabular}{lllllll}
\hline $\begin{array}{l}\text { Patient } \\
\text { No. }\end{array}$ & $\begin{array}{l}\text { Age, } \\
\text { years }\end{array}$ & Eye & Diagnosis & Comorbidities & Other toxicity & \multicolumn{1}{c}{$\begin{array}{l}\text { Ophthalmic } \\
\text { findings }\end{array}$} \\
\hline 1 & 61 & OS & $\begin{array}{l}\text { ovarian } \\
\text { cancer }^{2}\end{array}$ & $\begin{array}{l}\text { hypertension, } \\
\text { atrial fibrillation, } \\
\text { hyperlipidemia }\end{array}$ & $\begin{array}{l}\text { elevated CPK (CTCAE grade 1), cardiomyopathy, } \\
\text { reduced ejection fraction, acneiform rash (CTCAE } \\
\text { grade 1) }\end{array}$ & perfused CRVO \\
\hline 2 & 47 & OD & $\begin{array}{l}\text { Erdheim- } \\
\text { Chester }\end{array}$ & hypertension & $\begin{array}{l}\text { decreased ejection fraction, acneiform rash (CTCAE } \\
\text { grade 3) }\end{array}$ & $\begin{array}{l}\text { perfused CRVO, } \\
\text { optic nerve edema }\end{array}$ \\
\hline 3 & 31 & OD & GIST $^{1}$ & none & $\begin{array}{l}\text { acneiform rash (CTCAE grade 1), elevated CPK } \\
\text { (CTCAE grade 3) }\end{array}$ & perfused CRVO \\
\hline
\end{tabular}

CPK, creatine phosphokinase; CRVO, central retinal vein occlusion; CTCAE, Common Terminology Criteria for Adverse Events; GIST, gastrointestinal stromal tumor. ${ }^{1}$ Also on Gleevec. ${ }^{2}$ Starting dose $45 \mathrm{mg}$ b.i.d. and sequentially reduced to $15 \mathrm{mg}$ b.i.d. due to other toxicity.

Table 2. CRVO characteristics

\begin{tabular}{|c|c|c|c|c|c|c|c|c|}
\hline 1 & 7.1 months & $\begin{array}{l}\text { elevated } \\
(17.7 \mu \mathrm{M} / \mathrm{L})\end{array}$ & 13 days & heterozygous A1298C & $20 / 25$ & $\mathrm{CF}$ & $20 / 25$ & $4 \times$ aflibercept \\
\hline 2 & 8.3 months & $\begin{array}{l}\text { elevated } \\
(25 \mu \mathrm{M} / \mathrm{L})\end{array}$ & 8 days & homozygous A1298C & $20 / 40$ & $20 / 150$ & $20 / 40$ & $1 \times$ aflibercept \\
\hline
\end{tabular}

CF, count fingers; CRVO, central retinal vein occlusion; Hcy, homocysteine; MTHFR, methylene tetrahydrofolate reductase; VA, Snellen visual acuity. ${ }^{1}$ Normal level $<13 \mu \mathrm{M} / \mathrm{L}$.

A synergistic effect between coagulation disorders and the development of CRVO has been recognized; hypercoagulable workup can include testing for homocysteine and anticardiolipin antibodies, activated protein $\mathrm{C}$ resistance, and factor $\mathrm{V}$ Leiden testing [7-9]. A prospective case-control study found that patients with RVO were more likely to have hyperhomocysteinemia compared to controls [7], although some suggest that this is relevant to CRVO and not branch RVO [10]. Homocysteine is both atherogenic and prothrombotic and has been associated with a number of vascular events, including cerebrovascular, peripheral arterial, coronary heart disease, and venous thromboembolic disease $[11,12]$. The development of hyperhomocysteinemia has been linked to nutritional deficiencies (particularly vitamin cofactors), chronic medical conditions, smoking, medications (atorvastatin, nicotinic acid, fenofibrate, methotrexate), and genetic defects in the enzymes involved in homocysteine metabo- lism $[11,12]$. It has been proposed that supplementation (particularly with folate) may correct hyperhomocysteinemia, but its recommendation as a preventative measure is unclear.

The most common genetic etiology of hyperhomocysteinemia comes from the formation of the thermolabile variant of MTHFR, which has a population frequency of $5-14 \%$ and exhibits reduced enzymatic activity (C677T) [13]. A1298C is another variant that has also been linked, albeit to a lesser degree, to elevated homocysteine levels and coagulation disorders [14]. Reduced enzyme activity by these polymorphisms disturbs the normal metabolism of homocysteine to folate by L-methylfolate, thereby resulting in hyperhomocysteinemia. All 3 patients in this series demonstrated hyperhomocysteinemia in the context of an MTHFR polymorphism, and this may have contributed to their MEK inhibitor-associated vein occlusion. In 1 patient the homocysteine level was evaluated 1 month 

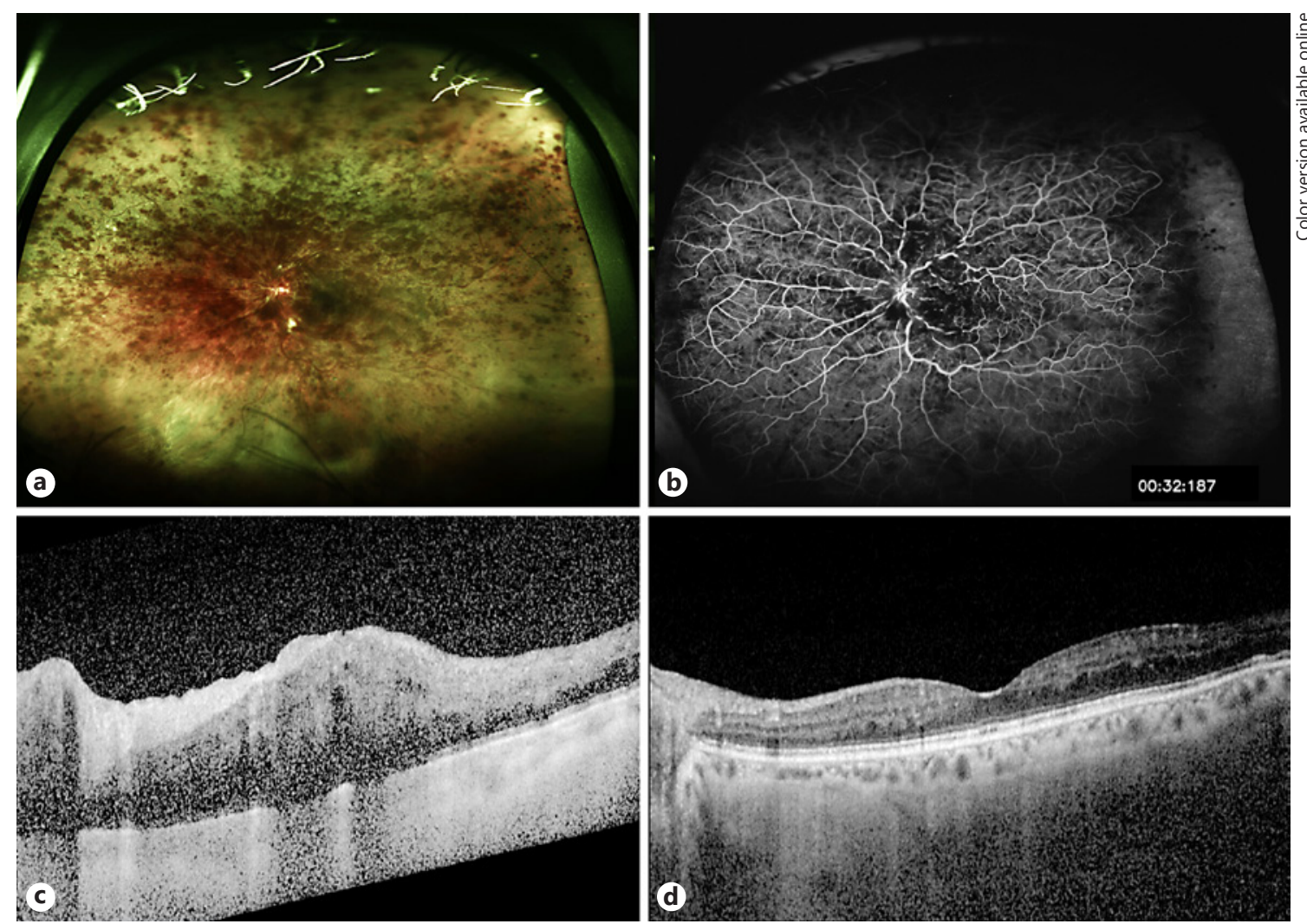

Fig. 1. Clinical images from case 1. a Fundus photography of left eye CRVO 7.1 months following the start of MEK inhibition. b Fluorescein angiography demonstrating perfused CRVO with blockage from intraretinal hemorrhage and tortuous venous vascular pattern. c Optical coherence tomography demonstrating characteristic macula edema corresponding to count fingers vision. d Forty-three months following four monthly aflibercept injections, vision had returned to 20/25 and optical coherence tomography demonstrated improvement in macula edema. CRVO, central retinal vein occlusion; MEK, mitogen-activated protein kinase kinase.

following the RVO, and it is possible this level may have been even higher closer to the time of the adverse event. Of note, CRVO events occurred at least 6 months following the initiation of MEK inhibition, suggesting a possible cumulative effect on homocysteine levels.

The mechanism for MEK inhibitor-associated CRVO is proposed to occur through inhibition of ERK activation and subsequent dysregulation of the brain-retina barrier [15]. There is evidence that homocysteine and the mitogen-activated protein kinase pathways interact and modulate downstream apolipoprotein E [16] and metalloproteinases [17], but it is unclear how this contributes to MEK inhibitor-associated RVO or whether MEK inhibition results in hyperhomocysteinemia.

The calculated prevalence of CRVO in MEK-inhibited patients at our institution is similar to the clinical trial calculations $(0.5 \%)$ and higher than the prevalence in the general population $(0.1 \%)$ [3]. In the general population, even the most favorable cases of RVO (those that are perfused) carry a 50\% likelihood of regaining baseline (or close to baseline) vision, and superior initial vision at the time of RVO is predictive of this $[4,18]$. For example, in the general population, an initial (at the time of RVO) vision of $20 / 200$ or less is unlikely to regain baseline vision. Contrary to this, all 3 patients in this cohort regained vision to baseline following a range of 2-4 anti-VEGF injections and drug cessation, including 1 patient who had an initial count finger vision. It is unclear whether cessation of the potentially life-preserving MEK inhibitor is warranted. It is difficult to draw generalizable conclusions from a cohort of only 3 patients, but it suggests that MEK inhibitor-associated CRVO patients may fare better in terms of visual rehabilitation compared to patients with CRVO from causes. This series also highlights that hyperhomocysteinemia (and even MTHFR polymorphisms) may be related to MEK inhibitor-associated CRVO, although it may not be the only contributing factor. It would be worthwhile for larger cohort studies to corroborate these findings. 


\section{Acknowledgements}

This study was supported by the Fund for Ophthalmic Knowledge, Research to Prevent Blindness and Cancer Center Support Grant (P30 CA008748). E.L. Diamond and D.M. Hyman are supported by the Frame Fund. The sponsor or funding organization had no role in the design or conduct of this research.

\section{Statement of Ethics}

The research protocol was approved by the Institutional Review Board of Memorial Sloan Kettering Cancer Center. All patients gave their informed consent to publication of their case.

\section{Disclosure Statement}

D.M. Hyman: consulting: Atara Biotherapeutics, Chugai Pharma, CytomX Therapeutics, Boehringer Ingelheim, AstraZeneca, Pfizer, Bayer, Genentech; research funding: Loxo Oncology, PUMA Biotechnology, AstraZeneca; travel: Genentech, Chugai Pharma. P. Chi: consulting and advisory: Deciphera; research funding: Novartis; travel: Deciphera. None of the other authors have any financial disclosures or conflicts.

\section{Author Contributions}

J.H. Francis: design and conduct of the study, collection, management, analysis, and interpretation of the data, and manuscript preparation. E.L. Diamond and P. Chi: collection of the data and manuscript review. K. Jaben and D.H. Abramson: manuscript review. D.M. Hyman: collection of the data and manuscript review.

\section{References}

1 Akinleye A, Furqan M, Mukhi N, Ravella P, Liu D. MEK and the inhibitors: from bench to bedside. J Hematol Oncol. 2013 Apr;6(1):27.

2 Francis JH, Habib LA, Abramson DH, Yannuzzi LA, Heinemann M, Gounder MM, et al. Clinical and Morphologic Characteristics of MEK Inhibitor-Associated Retinopathy: Differences from Central Serous Chorioretinopathy. Ophthalmology. 2017 Dec;124(12): 1788-98.

3 Klein R, Klein BE, Moss SE, Meuer SM. The epidemiology of retinal vein occlusion: the Beaver Dam Eye Study. Trans Am Ophthalmol Soc. 2000;98:133-41; discussion 141-3.

4 Hayreh SS, Podhajsky PA, Zimmerman MB Natural history of visual outcome in central retinal vein occlusion. Ophthalmology. 2011 Jan;118(1):119-133.e1-2.

5 The Central Vein Occlusion Study Group. Natural history and clinical management of central retinal vein occlusion. Arch Ophthalmol. 1997 Apr;115(4):486-91.

6 Purbrick RM, Osunkunle OA, Talbot DC, Downes SM. Ocular Toxicity of Mitogen-Activated Protein Kinase Inhibitors. JAMA Oncol. 2017 Feb;3(2):275-7.
7 Napal JJ, Neila S, Pérez-Montes R, Sierra I, Ruiz S, Hernández JL. The role of coagulation disorders in patients with retinal vein occlusion. QJM. 2016 Feb;109(2):97-102.

8 Pulido JS, Ward LM, Fishman GA, Goodwin JA, Froelich CJ, Sanghvi JP. Antiphospholipid antibodies associated with retinal vascular disease. Retina. 1987;7(4):215-8.

9 Tayyanipour R, Pulido JS, Postel EA, Lipkowitz JL, Pisciotta A, Braza E. Arterial vascular occlusion associated with factor $\mathrm{V}$ Leiden gene mutation. Retina. 1998;18(4):376-7.

10 Minniti G, Calevo MG, Giannattasio A, Camicione $\mathrm{P}$, Armani U, Lorini R, et al. Plasma homocysteine in patients with retinal vein occlusion. Eur J Ophthalmol. 2014 Sep-Oct;24(5):735-43.

11 Ray JG. Meta-analysis of hyperhomocysteinemia as a risk factor for venous thromboembolic disease. Arch Intern Med. 1998 Oct; 158(19):2101-6.

12 den Heijer M, Rosendaal FR, Blom HJ, Gerrits WB, Bos GM. Hyperhomocysteinemia and venous thrombosis: a meta-analysis. Thromb Haemost. 1998 Dec;80(6):874-7.

13 Kang SS, Passen EL, Ruggie N, Wong PW, Sora $\mathrm{H}$. Thermolabile defect of methylenetetrahydrofolate reductase in coronary artery disease. Circulation. 1993 Oct;88(4 Pt 1): 1463-9.
14 Yamada K, Chen Z, Rozen R, Matthews RG. Effects of common polymorphisms on the properties of recombinant human methylenetetrahydrofolate reductase. Proc Natl Acad Sci USA. 2001 Dec;98(26):14853-8.

15 Yang AH, Huang W. Retinal vein occlusion induced by a MEK inhibitor - impact of oxidative stress on the blood-retinal barrier. In: Lushchak VI, Gospodaryov DV, editors. Oxidative stress and diseases. London: IntechOpen; 2012. Available from: https://www.intechopen.com/ books/oxidative-stress-and-diseases/oxidative-stress-and-retinal-vein-occlusion.

16 Trusca VG, Mihai AD, Fuior EV, Fenyo IM, Gafencu AV. High levels of homocysteine downregulate apolipoprotein E expression via nuclear factor kappa B. World J Biol Chem. 2016 Feb;7(1):178-87.

17 Poddar R, Paul S. Novel crosstalk between ERK MAPK and p38 MAPK leads to homocysteine-NMDA receptor-mediated neuronal cell death. J Neurochem. 2013 Feb;124(4): 558-70.

18 Patz A. Argon laser photocoagulation for macular edema in branch vein occlusion. Am J Ophthalmol. 1984 Sep;98(3):374-5. 